\title{
Positive predictive value of peptic ulcer diagnosis codes in the Danish National Patient Registry
}

This article was published in the following Dove Press journal:

Clinical Epidemiology

5 May 2017

Number of times this article has been viewed

\author{
Søren Viborg' \\ Kirstine Kobberøe Søgaard' \\ Peter Jepsen ${ }^{1,2}$ \\ 'Department of Clinical Epidemiology, \\ ${ }^{2}$ Department of Hepatology and \\ Gastroenterology, Aarhus University \\ Hospital, Aarhus, Denmark
}

Background: Diagnoses of peptic ulcer are registered in the Danish National Patient Registry (DNPR) for administrative as well as research purposes, but it is unknown whether the coding validity depends on the location of the ulcer.

Objective: To validate the International Classification of Diseases, $10^{\text {th }}$ revision diagnosis codes of peptic ulcer in the DNPR by estimating positive predictive values (PPVs) for gastric and duodenal ulcer diagnoses.

Methods: We identified all patients registered with a hospital discharge diagnosis of peptic ulcer from Aarhus University Hospital, Denmark, in 1995-2006. Among them, we randomly selected 200 who had an outpatient gastroscopy at the time of ulcer diagnosis. We reviewed the findings from these gastroscopies to confirm the presence of peptic ulcer and its location. We calculated PPVs and corresponding 95\% confidence intervals (CIs) of gastric and duodenal ulcer diagnoses, using descriptions from the gastroscopic examinations as standard reference. Results: In total, 182 records (91\%) were available for review. The overall PPV of peptic ulcer diagnoses in DNPR was 95.6\% (95\% CI 91.5-98.1), with PPVs of 90.3\% (95\% CI 82.4-95.5) for gastric ulcer diagnoses, and $94.4 \%$ (95\% CI 87.4-98.2) for duodenal ulcer diagnoses. PPVs were constant over time.

Conclusion: The PPV of uncomplicated peptic ulcer diagnoses in the DNPR is high, and the location of the ulcers is registered correctly in most cases, indicating that the diagnoses are useful for research purposes.

Keywords: peptic ulcer, validation, positive predictive value, diagnosis, Danish National Patient Registry

\section{Introduction}

Peptic ulcer disease is common in the general population, with a reported annual incidence of $0.03 \%-0.19 \%,{ }^{1}$ and a lifetime prevalence of approximately $5 \%$ in Danish citizens aged $30-60$ years. ${ }^{2}$ Studies of risk factors, incidence, and prognosis are therefore important and often based on data from registries. ${ }^{3-7}$ Previous studies using registerbased data from the US, Canada, and UK have found positive predictive values (PPVs) of peptic ulcer diagnoses ranging from $57 \%-100 \%{ }^{8-10}$ Discharge diagnoses codes in the Danish National Patient Registry (DNPR) generally have a high validity, ${ }^{11}$ but the validity of uncomplicated peptic ulcer diagnoses (without bleeding or perforation) is uncertain, ${ }^{12,13}$ and no previous studies have aimed to investigate the validity according to the location of the ulcer, ie, duodenal or gastric. The aim of this quality assessment study is to examine the validity of peptic ulcer diagnosis codes in the DNPR overall, and by location of ulcer, by examining gastroscopic records from a Danish hospital.
Department of Clinical Epidemiology Aarhus University Hospital, Olof Palmes Allé 43-45, 8200 Aarhus N, Denmark $\mathrm{Tel}+45228 I \quad 1030$

Fax +45 87I 672I5

Email viborg.soren@gmail.com 


\section{Methods}

\section{Data sources}

The Danish Civil Registration system contains a unique 10-digit identifier for all Danish citizens, given at birth or immigration. The identifier provides information on the birthdate and sex of each citizen and allows linkage of patients between health care databases including the DNPR and the Aarhus Endoscopy Registry (AER). ${ }^{14}$

The DNPR contains discharge diagnoses from all hospital admissions in Denmark since 1977, and from emergency room and hospital outpatient visits since 1995. Through 1993, diagnoses were coded according to the International Classification of Diseases, $8^{\text {th }}$ revision (ICD-8), and thereafter the $10^{\text {th }}$ revision (ICD-10) has been used. After each admission, up to 20 diagnoses codes are recorded, one as primary and additional ones as secondary, as well as surgical procedures performed, and the date of admission and discharge. ${ }^{11}$ Endoscopies were recorded according to Danish Classification of Surgical Procedures from 1977 to 1995, and since 1996 according to the NOMESCO (Nordic Medico-Statistical Committee) classification of surgical procedures. ${ }^{15}$

AER is a research database containing records of endoscopic procedures performed at Aarhus University Hospital (AUH) in the period 1975-2007. The registry covers all gastroscopies, endoscopic retrograde cholangiopancreatography, and colonoscopies performed in the outpatient clinic at AUH. The registry comprises paper records with detailed descriptions of the endoscopic procedure and of findings of biopsies.

\section{Study population}

We searched for all patients with a first-time ulcer diagnosis (K25 and K26) at AUH in the endoscopic outpatient clinic, registered between 01.01.1995 and 31.12.2006. We excluded patients with previous diagnoses of peptic ulcer disease before the start of our inclusion period (see Supplementary materials for diagnosis codes). We then restricted the cohort to patients with at least one gastroscopic examination in relation to the contact leading to the ulcer diagnosis. We identified 382 patients with gastric ulcer and 271 patients with duodenal ulcer. Among them, we randomly selected 100 patients with gastric ulcer, and 100 with duodenal ulcer using the SAS RANUNI function (SAS Institute Inc., Cary, NC, USA). We obtained information on the date of admission, and the type of diagnosis code (primary or secondary). Ulcer diagnosis codes were further categorized as acute or chronic, and as uncomplicated or complicated (ie, bleeding or perforated ulcers).

\section{Record review}

We reviewed records of gastroscopic examinations performed during the hospital contact for peptic ulcer. We considered the diagnosis confirmed if the endoscopist described gastric or duodenal ulcers, or ulcer cicatrices to indicate recent peptic ulcer disease. ${ }^{16}$ Ulcers of the fundus, corpus, or antrum were considered as gastric, and ulcers in the pyloric canal or duodenum as duodenal. If both gastric and duodenal ulcers were described, we classified the ulcer as combined, ${ }^{16}$ and we considered the diagnosis code confirmed whether it was a code for gastric ulcer or duodenal ulcer. If several gastroscopic examinations had been performed during the same admission, information from all the examinations was obtained. All gastroscopic records were thoroughly investigated by SV, who was blinded to the diagnosis codes recorded in the DNPR. In case of uncertainty about the true diagnosis, the endoscopic description was discussed with an experienced surgeon.

According to Danish law at the time the study was conducted, quality assessment studies such as this did not require informed consent to review patients' medical records. All records were reviewed with confidentiality and discretion, as required.

\section{Statistical analyses}

The main outcome of the study was PPV of peptic ulcer diagnoses, defined as the proportion of patients with a peptic ulcer discharge diagnosis in the DNPR who had ulcer disease confirmed by endoscopy. We stratified ulcers by location (gastric or duodenal), complication (uncomplicated or complicated ulcer), time of diagnosis (1995-1998, 1999-2002, 2003-2006), and type of diagnosis (primary or secondary). We calculated binomial exact $95 \%$ confidence intervals (CIs) corresponding to the PPVs. Data were analyzed with Stata software (version 13.0; StataCorp LP, College Station, TX, USA).

\section{Results}

\section{Review process}

We located and reviewed the endoscopic records of 182 (91\%) patients, 93 patients with gastric and 89 patients with duodenal ulcers (Table 1). The remaining 18 patients without an endoscopic record were left out of the analyses, but the characteristics of all 200 sampled patients are listed in Table 1.

\section{Patient characteristics}

Among the 182 included patients the median age at peptic ulcer diagnosis was 60 years (interquartile range: 48-71 
Table I Characteristics of 200 outpatients with a first-time diagnosis of peptic ulcer disease endoscopically examined at Aarhus University Hospital, Denmark during 1995-2006

\begin{tabular}{|c|c|c|}
\hline Characteristics & $\begin{array}{l}\text { Patients } \\
\text { sampled, n (\%) }\end{array}$ & $\begin{array}{l}\text { Patients } \\
\text { included, n (\%) }\end{array}$ \\
\hline$\overline{\text { All }}$ & $200(100)$ & $182(100)$ \\
\hline \multicolumn{3}{|l|}{ Sex } \\
\hline Female & $85(43)$ & $79(43)$ \\
\hline Male & $115(58)$ & $103(57)$ \\
\hline \multicolumn{3}{|c|}{ Age at ulcer diagnosis } \\
\hline $0-39$ years & $33(17)$ & $27(15)$ \\
\hline $40-59$ years & $70(35)$ & $65(36)$ \\
\hline $60+$ years & $97(49)$ & $90(49)$ \\
\hline \multicolumn{3}{|l|}{ Year of diagnosis } \\
\hline $1995-1998$ & $69(35)$ & $62(34)$ \\
\hline 1999-2002 & $69(35)$ & $59(32)$ \\
\hline $2003-2006$ & $62(31)$ & $61(34)$ \\
\hline \multicolumn{3}{|c|}{ Recorded location } \\
\hline \multicolumn{3}{|l|}{ of ulcer } \\
\hline Gastric & $100(50)$ & $93(5 \mathrm{I})$ \\
\hline Duodenal & $100(50)$ & $89(49)$ \\
\hline \multicolumn{3}{|c|}{$\begin{array}{l}\text { Recorded status of } \\
\text { ulcer in the DNPR }\end{array}$} \\
\hline Acute & $79(40)$ & $71(39)$ \\
\hline Chronic & $63(32)$ & $57(31)$ \\
\hline Unspecified & $58(29)$ & $54(30)$ \\
\hline \multicolumn{3}{|c|}{ Complicated ulcer } \\
\hline Yes & $2(1)$ & $I(I)$ \\
\hline No & $198(99)$ & $181(99)$ \\
\hline
\end{tabular}

Abbreviation: DNPR, Danish National Patient Registry.

years), and more men (57\%) than women $(43 \%)$ were examined. According to the DNPR, 71 patients (39\%) had acute ulcers, 57 (31\%) had chronic ulcers, and $54(30 \%)$ had unspecified ulcers, whereas only one patient had a complicated ulcer (Table 1).

\section{Validity of peptic ulcer diagnosis codes}

In total, 174 of 182 patients diagnosed with peptic ulcer had endoscopically confirmed ulcer disease, corresponding to a PPV of 95.6\% (91.5-98.1) (Table 2). However, not all diagnoses were correctly classified regarding location of the ulcer. The PPV of gastric ulcer diagnoses was $90.3 \%$ (82.4-95.5), and the PPV of duodenal ulcer diagnosis was $94.4 \%$ (87.4-98.2). The validity of peptic ulcer diagnoses was constant over time, and primary diagnoses were highly valid (96.5\% [92.6-98.7]). The PPV of the ten secondary diagnoses was imprecisely estimated (80.0\% [44.4-97.5]) (Table 2). Among the confirmed peptic ulcers, we found ulcer cicatrices indicating recent peptic ulcer disease in ten patients (5.5\%) (Table S1). The eight patients (4.4\%) with no peptic ulcer disease had gastritis $(\mathrm{n}=7)$ and esophagitis $(\mathrm{n}=1)$ (Table S1).

\section{Discussion}

We found outpatient peptic ulcer diagnosis codes in the DNPR to be highly valid in terms of presence and location of the ulcer. A minor part of the ulcer diagnoses covered ulcer cicatrices and no active ulcer disease. The high validity was constant over time.

Several studies previously elucidated validity of registerbased diagnoses of peptic ulcer disease. A study from Canada found PPVs of hospital-based peptic ulcer diagnoses ranging from $57 \%$ to $70 \%,{ }^{8}$ which is substantially lower than our estimates, possibly caused by differences in study populations or quality of registries. Also, a study from the US reported PPVs of $61 \%-66 \%,{ }^{9}$ but they did not restrict inclusion to patients who were examined endoscopically, and diagnoses were only confirmed in case of active ulcer disease. In agreement with our findings, peptic ulcer disease diagnoses from a UK primary health care database, were confirmed endoscopically or visually during surgical procedures among $92 \%-100 \%$ of patients. ${ }^{10}$ While the PPV of a given condition depends on its prevalence in the study population, the 1-year ulcer prevalence is comparable in the UK and Denmark and therefore unlikely to explain the difference in PPV. ${ }^{1}$ Two previous studies reported the validity of ulcer diagnoses in the DNPR. The first was designed to examine incidence and mortality rates in patients with complicated and uncomplicated peptic ulcers. It reported PPVs of uncomplicated gastric ulcer (75\%) and uncomplicated duodenal ulcer $(71 \%),{ }^{12}$ but the inclusion criteria and criteria for confirmation of ulcers were not reported. The second study reported an overall PPV of ulcer disease of $98 \%$, but they did not report confirmation criteria, nor did they validate the diagnoses by location. ${ }^{13}$

Our study has several strengths. In Denmark, we have universal and equal access to health care services, which minimizes the risk of referral and selection bias, and DNPR is generally of high completeness and quality. ${ }^{11}$ The reviewer of the endoscopic records was blinded to the location of ulcer according to the DNPR, minimizing the risk of observer bias. ${ }^{17}$

Our study has several potential limitations. We had access to endoscopic records only from one gastroenterology department at a university hospital, and we restricted inclusion to endoscopically examined patients. Possibly, some patients are diagnosed with peptic ulcer in the DNPR without gastroscopic confirmation, which is why the high PPV we found may not be applied to all diagnoses recorded in the DNPR. ${ }^{11}$ In addition, because our sample only included patients diagnosed at an endoscopic outpatient clinic, the 
Table 2 Positive predictive values of ICD-10 codes of recent peptic ulcers among 200 selected patients at Aarhus University Hospital, Denmark during 1995-2006, validated using descriptions from the gastroscopic examinations as standard reference

\begin{tabular}{|c|c|c|c|c|c|}
\hline & $\begin{array}{l}\text { Patients } \\
\text { sampled, } n\end{array}$ & $\begin{array}{l}\text { Patients } \\
\text { included, } \mathbf{n}\end{array}$ & $\begin{array}{l}\text { Confirmed } \\
\text { diagnoses, } n\end{array}$ & PPV (\%) & $95 \% \mathrm{Cl}$ \\
\hline Overalla & 200 & 182 & 174 & 95.6 & $91.5-98.1$ \\
\hline \multicolumn{6}{|c|}{ Location of ulcer ${ }^{b}$} \\
\hline Gastric & 100 & 93 & 84 & 90.3 & $82.4-95.5$ \\
\hline Duodenal & 100 & 89 & 84 & 94.4 & 87.4-98.2 \\
\hline \multicolumn{6}{|c|}{ Type of diagnosis } \\
\hline Primary & 188 & 172 & 166 & 96.5 & $92.6-98.7$ \\
\hline Secondary & 12 & 10 & 8 & 80.0 & 44.4-97.5 \\
\hline \multicolumn{6}{|c|}{ Time of diagnosis } \\
\hline $1995-1998$ & 69 & 62 & 60 & 96.8 & $88.8-99.6$ \\
\hline 1999-2002 & 69 & 59 & 55 & 93.2 & $83.5-98.1$ \\
\hline $2003-2006$ & 62 & 61 & 59 & 96.7 & $88.7-99.6$ \\
\hline
\end{tabular}

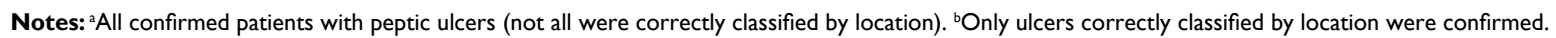

Abbreviations: PPV, positive predictive value; $\mathrm{Cl}$, confidence interval; ICD-10, International Classification of Diseases, $10^{\text {th }}$ revision.

frequency of complicated ulcers was low. Accordingly, we were unable to conclude on the validity of complicated ulcer diagnoses. Future studies need to investigate the validity of complicated peptic ulcer diagnosis codes, as well as any potential differences in quality of coding between specialist and non-specialist clinics.

\section{Conclusion}

Finally, we conclude that outpatient diagnosis codes of uncomplicated peptic ulcer disease in the DNPR are highly valid for patients examined with gastroscopy. We found a high PPV of peptic ulcer diagnoses including localization as gastric or duodenal. The high PPVs indicate that the diagnoses have high specificity and are suitable for research purposes.

\section{Acknowledgments}

This work was funded by the Program for Clinical Research Infrastructure (PROCRIN) established by the Lundbeck Foundation and the Novo Nordisk Foundation. The sponsor did not influence the design or conduct of the study; collection, management, analysis, and interpretation of the data; preparation, review, or approval of the manuscript; or the decision to submit the manuscript for publication.

\section{Author contributions}

KKS conceived the idea for the study. All authors designed the study. SV collected, managed, and analyzed the data. All authors interpreted the results, drafted the article, gave final approval of the version to be published, and agree to be accountable for all aspects of the work.

\section{Disclosure}

The authors report no conflicts of interest in this work.

\section{References}

1. Sung JJ, Kuipers EJ, El-Serag HB. Systematic review: the global incidence and prevalence of peptic ulcer disease. Aliment Pharmacol Ther. 2009;29(9):938-946.

2 Rosenstock SJ, Jorgensen T. Prevalence and incidence of peptic ulcer disease in a Danish County--a prospective cohort study. Gut. 1995;36(6):819-824.

3. Dall M, Schaffalitzky de Muckadell OB, Lassen AT, Hallas J. There is an association between selective serotonin reuptake inhibitor use and uncomplicated peptic ulcers: a population-based case-control study. Aliment Pharmacol Ther. 2010;32(11-12):1383-1391.

4. Ruigomez A, Johansson S, Nagy P, Martin-Perez M, Rodriguez LA. Risk of uncomplicated peptic ulcer disease in a cohort of new users of low-dose acetylsalicylic acid for secondary prevention of cardiovascular events. BMC Gastroenterol. 2014;14:205.

5. Sogaard KK, Farkas DK, Pedersen L, Lund JL, Thomsen RW, Sorensen HT. Long-term risk of gastrointestinal cancers in persons with gastric or duodenal ulcers. Cancer Med. 2016;5(6):1341-1351.

6. Thomsen RW, Riis A, Munk EM, Norgaard M, Christensen S, Sorensen HT. 30-day mortality after peptic ulcer perforation among users of newer selective COX-2 inhibitors and traditional NSAIDs: a population-based study. Am J Gastroenterol. 2006;101(12):2704-2710.

7. Sung JJ, Tsoi KK, Ma TK, Yung MY, Lau JY, Chiu PW. Causes of mortality in patients with peptic ulcer bleeding: a prospective cohort study of 10,428 cases. Am J Gastroenterol. 2010;105(1):84-89.

8. Lopushinsky SR, Covarrubia KA, Rabeneck L, Austin PC, Urbach DR. Accuracy of administrative health data for the diagnosis of upper gastrointestinal diseases. Surg Endosc. 2007;21(10):1733-1737.

9. Andrade SE, Gurwitz JH, Chan KA, et al. Validation of diagnoses of peptic ulcers and bleeding from administrative databases: a multihealth maintenance organization study. J Clin Epidemiol. 2002;55(3): 310-313.

10. Margulis AV, Garcia Rodriguez LA, Hernandez-Diaz S. Positive predictive value of computerized medical records for uncomplicated and complicated upper gastrointestinal ulcer. Pharmacoepidemiol Drug Saf. 2009;18(10):900-909.

11. Schmidt M, Schmidt SA, Sandegaard JL, Ehrenstein V, Pedersen L, Sorensen HT. The Danish National Patient Registry: a review of content, data quality, and research potential. Clin Epidemiol. 2015;7: 449-490. 
12. Lassen A, Hallas J, Schaffalitzky de Muckadell OB. Complicated and uncomplicated peptic ulcers in a Danish county 1993-2002: a population-based cohort study. Am J Gastroenterol. 2006;101(5): 945-953.

13. Thygesen SK, Christiansen CF, Christensen S, Lash TL, Sorensen HT. The predictive value of ICD-10 diagnostic coding used to assess Charlson comorbidity index conditions in the population-based Danish national registry of patients. BMC Med Res Methodol. 2011; $11: 83$.

14. Pedersen CB. The Danish civil registration system. Scand J Public Health. 2011;39(7 Suppl):22-25.
15. Nordic Medico Statistical Committee (NOMESCO). NOMESCO classification of surgical procedures. 16th ed. Copenhagen: NOMESCO; 2011. Available from: http://www.nordclass.se/NCSP_1_16.pdf. Accessed January 20, 2017.

16. Rosenstock SJ, Jorgensen T, Bonnevie O, Andersen LP. Does helicobacter pylori infection explain all socio-economic differences in peptic ulcer incidence? Genetic and psychosocial markers for incident peptic ulcer disease in a large cohort of Danish adults. Scand J Gastroenterol. 2004;39(9):823-829.

17. Delgado-Rodriguez M, Llorca J. Bias. J Epidemiol Community Health. 2004;58(8):635-641. 


\section{Supplementary materials}

Hospital, department, diagnosis and

\section{procedure codes}

- Hospital code: 7003 (Aarhus District General Hospital, Nørrebrogade 44, 8000 Aarhus C, Denmark).

- Department codes: 7003287 (Endoscopic Outpatient Clinic, Aarhus District General Hospital).

- We included patients with the following International Classification of Diseases, $10^{\text {th }}$ revision (ICD-10) peptic ulcer diagnoses: all peptic ulcers (K25 or K26). Specifically gastric ulcers (K25) and duodenal ulcers (K26). Specifically uncomplicated ulcers (K25.3, K25.7, K25.9, K26.3, K26.7, K26.9) and complicated ulcers (K25.0, K25.1, K25.2, K25.4, K25.5, K25.6, K26.0, K26.1, K26.2, K26.4, K26.5, K26.6).

- We used the following ICD-8 diagnosis codes to exclude patients with an ulcer diagnosis before 01.01.1995: 531 gastric ulcer, 532 duodenal ulcer, 533 peptic ulcer site unspecified, 534 gastrojejunal ulcer.

- Procedure codes for gastroscopic examination: ICD-8: 91010 and ICD-10: KUJD.

Table SI Description of endoscopic findings among 182 patients with a diagnosis code of gastric or duodenal ulcer

\begin{tabular}{|c|c|c|c|c|c|c|c|c|}
\hline \multirow{2}{*}{$\begin{array}{l}\text { Discharge } \\
\text { diagnosis }\end{array}$} & \multicolumn{8}{|c|}{ Endoscopic description, n (\%) } \\
\hline & Gastric ulcer & $\begin{array}{l}\text { Duodenal } \\
\text { ulcer }\end{array}$ & $\begin{array}{l}\text { Gastric ulcer and } \\
\text { duodenal ulcer }\end{array}$ & $\begin{array}{l}\text { Gastric } \\
\text { cicatrices }\end{array}$ & $\begin{array}{l}\text { Duodenal } \\
\text { cicatrices }\end{array}$ & Gastritis & Esophagitis & Total \\
\hline Gastric ulcer & $72(77)$ & $2(2)$ & $3(3)$ & $9(10)$ & $0(0)$ & $6(6)$ & $I(I)$ & $93(100)$ \\
\hline Duodenal ulcer & $4(4)$ & 81 (9l) & $2(2)$ & $0(0)$ & I (I) & I (I) & $0(0)$ & $89(100)$ \\
\hline
\end{tabular}

Clinical Epidemiology

\section{Publish your work in this journal}

Clinical Epidemiology is an international, peer-reviewed, open access, online journal focusing on disease and drug epidemiology, identification of risk factors and screening procedures to develop optimal preventative initiatives and programs. Specific topics include: diagnosis, prognosis, treatment, screening, prevention, risk factor modification,

Submit your manuscript here: https://www.dovepress.com/clinical-epidemiology-journa
Dovepress

systematic reviews, risk and safety of medical interventions, epidemiology and biostatistical methods, and evaluation of guidelines, translational medicine, health policies and economic evaluations. The manuscript management system is completely online and includes a very quick and fair peer-review system, which is all easy to use. 